\title{
Effects of $\beta$-carotene supplementation for six months on clinical and laboratory parameters in patients with cystic fibrosis
}

\author{
S Renner, R Rath, P Rust, S Lehr, Th Frischer, I Elmadfa, I Eichler
}

\begin{abstract}
Background-Patients with cystic fibrosis (CF) have significantly decreased plasma concentrations of nutrient antioxidant vitamins, especially of $\beta$-carotene, which is thought to result from fat malabsorption and chronic pulmonary inflammation. The aim of this double blind, placebo controlled study was to investigate the effect of oral $\beta$-carotene supplementation for six months on clinical parameters.

Methods-Twenty four patients with CF were randomised to receive $\beta$-carotene $1 \mathrm{mg} / \mathrm{kg} /$ day (maximum $50 \mathrm{mg} / \mathrm{day}$ ) for three months (high dose supplementation) and $10 \mathrm{mg} / \mathrm{day}$ for a further three months (low dose supplementation) or placebo. At monthly follow up visits the plasma $\beta$-carotene concentration, total antioxidant capacity, malondialdehyde (MDA) as a marker of lipid peroxidation, and clinical parameters (ShwachmannKulczycki score, body mass index (BMI), height, and lung function $\left.\left(\mathrm{FEV}_{1}\right)\right)$ were assessed. The number of pulmonary exacerbations requiring antibiotic treatment (in days) three months before and during the study were evaluated.
\end{abstract}

University Children's Hospital, Währinger Gürtel 18-20, 1090

Vienna, Austria

S Renner

R Rath

Th Frischer

I Eichler

Institute of Nutrition Vienna, Althanstrasse 14, 1090 Vienna,

Austria

P Rust

I Elmadfa

Institute for Medical Statistics, University of

Vienna,

Schwarzspanierstraße

17, 1090 Vienna,

Austria

S Lehr

Correspondence to: Dr I Eichler

irmgard.eichler@akh-wien.ac.at

Received 12 January 2000 Returned to authors 16 March 2000

Revised version received

11 September 2000

Accepted for publication

14 September 2000
Results-The plasma concentration of $\beta$-carotene increased significantly to the normal range during the three months of high dose supplementation (baseline $0.08(0.04) \mu \mathrm{mol} / 1$ to $0.56(0.38) \mu \mathrm{mol} / 1$; $\mathrm{p}<0.001$ ) but decreased to 0.32 $(0.19) \mu \mathrm{mol} / 1$ in the period of low dose supplementation. Initially raised plasma levels of MDA fell to normal levels and the total antioxidant capacity showed a nonsignificant trend towards improvement during high dose supplementation. Antibiotic treatment decreased significantly in the supplementation group from 14.5 (14.9) days/patient during the three months before the study to 9.8 (10.3) days/ patient during high dose supplementation $(p=0.0368)$ and to 10.5 (9.9) days/patient during low dose supplementation, but increased in the placebo group. The Shwachmann-Kulczycki score, lung function, and BMI did not show any changes in either of the treatment groups. No adverse events were observed during the study period.

Conclusion-Oral $\beta$-carotene supplementation in a dose of $1 \mathrm{mg} / \mathrm{kg} / \mathrm{day}$ only was effective in normalising the plasma concentration of $\beta$-carotene and resulted in a decrease in pulmonary exacerbations. These data suggest that patients with $\mathrm{CF}$ may benefit clinically from supplementation with $\beta$-carotene and further studies are warranted.

(Thorax 2001;56:48-52)

Keywords: cystic fibrosis; $\beta$-carotene supplementation; pulmonary exacerbations; clinical parameters; lung function

Cystic fibrosis (CF) is characterised by its genetically determined abnormalities of mucus secretion, chronic bacterial endobronchial infection, and a chronic predominantly neutrophilic inflammatory response combined with exocrine pancreatic insufficiency in 85$90 \%$ of patients.

In the presence of chronic lung inflammation, increased oxygen free radical generation from activated neutrophils is assumed to occur $^{1-5}$ and is postulated to cause an increased rate of turnover of nutrient antioxidants and the enzymatic scavenger system, resulting in an oxidant-antioxidant imbalance. ${ }^{4-10}$ In addition, exocrine pancreatic insufficiency may cause deficiencies in fat soluble antioxidants such as vitamin $\mathrm{E}$ and $\beta$-carotenoids. The level of nutrient antioxidants is therefore significantly impaired in many patients with $\mathrm{CF}^{7}{ }^{11-13}$ It has been suggested that oxygen free radicals, in conjunction with impaired antioxidant protection, may be important mediators of the chronic lung tissue damage in $\mathrm{CF} .{ }^{10}$

Multivitamin supplementation, including retinol 1-2 mg/day, tocopherol 3-14 mg/day, and ascorbate $50-200 \mathrm{mg} /$ day, in addition to the average western European diet which includes $2-5 \mathrm{mg} \beta$-carotene per day, does not always normalise these deficiencies. ${ }^{6811}$ For a number of years supplementation with tocopherol (5-15 mg/kg/day) has been an accepted part of the treatment of CF. ${ }^{14}{ }^{15}$ However, recent data have shown that patients with $\mathrm{CF}$ adequately supplemented with vitamin $\mathrm{E}$ but with an uncorrected $\beta$-carotene deficiency still exhibit increased lipid peroxidation. ${ }^{7816} \mathrm{In}$ addition to its function as provitamin A, $\beta$-carotene also exerts biological properties as an enhancer of immune functions. ${ }^{17}$ Since antioxidants are thought to have the potential to protect against tissue damage and immune dysfunction, ${ }^{18}$ we hypothesised that, by correcting the $\beta$-carotene deficiency, patients with $\mathrm{CF}$ may benefit clinically through a reduction in acute pulmonary exacerbations. 
The primary aim of our study was to assess whether oral supplementation with $\beta$-carotene normalises the plasma concentration of $\beta$-carotene in addition to reducing the number of pulmonary exacerbations in patients with CF. Since long term studies of $\beta$-carotene supplementation in patients with CF are limited, ${ }^{7819}$ the dosage needed to achieve a $\beta$-carotene level comparable to that in healthy control subjects is not well defined. The second aim of the study was therefore to assess whether, after normalisation of the serum $\beta$-carotene concentration has been achieved, high dose supplementation can be reduced to low dose supplementation to maintain the $\beta$-carotene levels within the normal range.

\section{Methods}

Between July 1995 and October 199624 patients with CF (18 female) of mean age 11.7 years (range 6.7-27.7) were enrolled for six months in a randomised, double blind, placebo controlled study.

To conceal treatment allocation all patients received capsules of identical appearance. Thirteen patients (nine female) of mean age 12.8 years (range 6.8-27.7) were randomised to receive $\beta$-carotene supplementation in a dose of $1 \mathrm{mg} / \mathrm{kg} /$ day (maximum $50 \mathrm{~kg} /$ day) for three months (high dose supplementation) followed by a period of a further three months with a weight independent low dose regime of $10 \mathrm{mg} /$ day $\beta$-carotene in a single dose (all-trans $100 \% \beta$-carotene was used and mixed with starch 1:1). The prepared capsules had to be taken in the morning with a fat containing meal after the patients had taken their pancreatic enzymes. Eleven patients with CF (nine female) of mean age 10.5 years (range $6.7-17.3)$ received placebo for six months. The placebo capsules were prepared with starch.

To assess compliance a bottle containing the amount of $\beta$-carotene capsules necessary to cover the period from one visit to the other was handed over to the patients or their parents at every visit including an explanation from the doctor as to how it should be given. To determine the intake the number of capsules remaining was counted at each visit.

All patients had a typical history of CF and the diagnosis was established from iontophoretic sweat chloride levels of $>60 \mathrm{mEq} / \mathrm{l}$ in a pilocarpine induced sweat sample of $>100 \mathrm{mg} .{ }^{20}$ Eight of 13 patients in the supplementation group and six of 11 in the placebo group were chronically infected with Pseudomonas aeruginosa and/or Staphylococcus aureus.

Any previous supplementation with multivitamins, $\alpha$-tocopherol, or pancreatic enzymes remained unchanged (daily intake of $1-2 \mathrm{mg}$ retinol, 50-200 $\mathrm{mg}$ ascorbate, $110-400 \mathrm{mg}$ $\alpha$-tocopherol) during the study period.

At the beginning of the study and at monthly follow up visits the clinical status was assessed by the Shwachmann-Kulczycki score ${ }^{21}$ without reviewing the chest radiographs to give a score range of $0-75$. Pulmonary function tests were performed as follows: forced vital capacity (FVC) and forced expiratory volume in one second $\left(\mathrm{FEV}_{1}\right)$ were recorded in the form of a maximum expiratory flow volume curve (Masterlab; E Jäger, Wuerzburg, Germany) according to the American Thoracic Society (ATS) standards. ${ }^{22}$ The best of the three efforts was used for calculations. The results are expressed as percentage predicted normal values based on accepted reference standards. ${ }^{22} 23$

At each clinical visit height and weight were recorded for each patient and blood samples were taken for measurement of $\beta$-carotene, retinol, MDA, total antioxidative capacity, red and white blood count, and serum chemistry. Height was measured using a Harpenden stadiometer, recording the mean of three consecutive measurements, and was expressed as age independent $\mathrm{z}$ score (delta height standard deviation score) with reference to the population specific reference data of Prader et $a l .^{24}$ Weight was expressed as body mass index (BMI, weight $(\mathrm{kg}) /$ height $\left.\left(\mathrm{m}^{2}\right)\right)$.

Plasma concentrations of $\beta$-carotene, retinol, and $\alpha$-tocopherol were determined by HPLC according to the method of Jakob and Elmadfa. ${ }^{25}$ The interassay coefficient of variation was $<9 \%$. The total antioxidative capacity was measured by a modification of the photometric method according to Rice-Evans and Miller ${ }^{26}$ with an interassay coefficient of variation of $<5 \%$. MDA as a marker of lipid peroxidation ${ }^{27}$ was determined by HPLC using the method of Wong et al. ${ }^{28}$ The interassay coefficient of variation was $<8 \%$.

To examine the potential beneficial effect of $\beta$-carotene supplementation on the frequency of pulmonary exacerbations, the numbers of days on which systemic (oral or intravenous) antibiotics were used for the treatment of an acute pulmonary exacerbation were evaluated three months before and during the six months of the study. In this study population antibiotics were prescribed solely by the doctors at the Vienna CF centre (SR, IE). Pulmonary exacerbations were defined by weight loss, anorexia, increased cough, increased respiratory rate, increased sputum production, fever with or without evidence of new pulmonary infiltrates, deterioration of oxygen saturation and of lung function. Carotenodermia was assessed by examining the palms and soles of the patients and by questioning parents and/or patients about any changes in skin colour.

Approval of the institutional review boards was granted for the study and informed consent was obtained from each patient and/or their parents.

\section{STATISTICAL METHODS}

To examine the influence of treatment on $\mathrm{FEV}_{1}$, total antioxidative capacity, antibiotic days, $\mathrm{z}$ score of height, BMI, Shwachmann score, and $\beta$-carotene concentration, baseline values and mean values over the following two periods of three months each were analysed. The differences between baseline values and those following treatment ( 12 weeks average minus baseline value and 24 weeks average minus baseline) were calculated. Analysis of variance (ANOVA) with the grouping factor treatment (two levels: placebo/supplementation) and the repeated factor time (two levels) was performed for the 
Table 1 Mean (SD) baseline data

\begin{tabular}{llll}
\hline & $\begin{array}{l}\text { Supplementation } \\
\text { group }(n=13)\end{array}$ & $\begin{array}{l}\text { Placebo group } \\
(n=11)\end{array}$ & p value \\
\hline Age & $14.6(7.7)$ & $10.5(4.0)$ & 0.115 \\
FEV $_{1}(\%$ predicted) & $72.2(32.2)$ & $83.7(21.1)$ & 0.324 \\
z score of height & $-1.13(1.08)$ & $-1.12(0.75)$ & 0.977 \\
BMI $\left(\mathrm{kg} / \mathrm{m}^{2}\right)$ & $16.8(3.5)$ & $16.8(3.1)$ & 0.979 \\
Shwachmann-Kulczycki score & $53.7(13.0)$ & $61.6(6.2)$ & 0.067 \\
Number of antibiotic days & $14.5(14.9)$ & $10.5(11.2)$ & 0.481 \\
$\beta$-carotene plasma concentration $(\mu \mathrm{mol} / \mathrm{l})$ & $0.08(0.04)$ & $0.07(0.03)$ & 0.838 \\
Total antioxidative capacity $(\mathrm{nmol})$ & $0.85(0.34)$ & $0.86(0.26)$ & 0.844 \\
\hline
\end{tabular}

$\mathrm{FEV}_{1}=$ forced expiratory volume in one second; $\mathrm{BMI}=$ body mass index.

differences between baseline values and those following treatment for each variable separately. Confidence intervals for the difference between the supplementation and placebo groups in differences between baseline values and those following treatment were estimated for 12 and 24 weeks.

Since the distributions of all variables (except BMI) are optically symmetrical, no transformation had to be done. However, ANOVA was also performed on square root transformed data. The results remained the same qualitatively.

The baseline characteristics of the two groups were compared using $t$ tests and the results expressed as mean (SD). No adjustment for multiple testing was performed.

\section{Results}

The baseline characteristics are shown in table 1. There was no significant difference between the supplementation and placebo group in the $\beta$-carotene concentration $(p=0.838)$, the main variables $\left(\mathrm{FEV}_{1} \%\right.$ predicted, total antioxidative capacity, antibiotic days) and the secondary variables (z score of height, BMI, Shwachmann score). The results of the main variables are summarised in table 2 .

The patients had significantly lower mean (SD) plasma $\beta$-carotene concentrations $(0.08$ $(0.04) \mu \mathrm{mol} / \mathrm{l})$ than healthy controls $(0.27$ (0.14) $\mu \mathrm{mol} / \mathrm{l} ; \mathrm{p}<0.001) .{ }^{29}$ After one month a significant increase in plasma concentration from $0.08(0.04) \mu \mathrm{mol} / 1$ to $0.51(0.30) \mu \mathrm{mol} / 1$ $(\mathrm{p}<0.001)$ in the supplementation group was observed. During the three months of high dose supplementation the plasma concentration of $\beta$-carotene plateaued without further increase $(0.56 \quad(0.38) \mu \mathrm{mol} / \mathrm{l})$. During the following three months of low dose supplementation the $\beta$-carotene concentration decreased to $0.32(0.19) \mu \mathrm{mol} / 1$ and remained at this

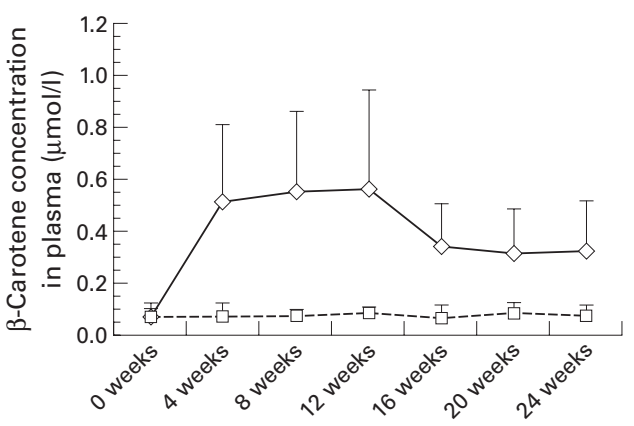

Figure 1 Mean (SD) plasma concentrations of $\beta$-carotene in patients with $C F$ supplemented with $\beta$-carotene $(\diamond)$ and those given placebo (प) during 12 weeks of high dose treatment and 12 weeks of low dose treatment; $p<0.001$.

lower range until the end of the study ( $p$ value of the group effect $<0.0001$, $p$ value of the time/group interaction $=0.0476$; fig 1 ). The confidence intervals of the group differences at 12 and 24 weeks were 14.7 to 31.1 and 8.89 to 19.59 , respectively.

In the three months before the study the number of days of treatment with systemic antibiotics necessitated by an acute pulmonary exacerbation was 14.5 (14.9) per patient in the supplementation group and 10.5 (11.2) per patient in the placebo group (not significant). During the 24 weeks of $\beta$-carotene supplementation a significant difference between the two groups was detected. Patients in the $\beta$-carotene group received systemic antibiotics to treat an acute pulmonary exacerbation for 9.8 (10.3) days in the high dose period and for 10.5 (9.9) days per patient in the low dose period, while patients in the placebo group received systemic antibiotics for 24.8 (19.1) days in the first three months and for 18.5 (15.8) days per patient in the last three months (fig 2). This difference was more pronounced after the first 12 weeks of high dose $\beta$-carotene supplementation (CI of group difference -35.5 to $-2.23 ; \mathrm{p}=0.0368$ ) than after the following 12 weeks of low dose supplementation (CI after 24 weeks -26.7 to 3.07 , group $\mathrm{p}$ value $=0.050$ )

After three months of high dose supplementation there was a non-significant trend towards improvement in the total antioxidative capacity in the supplementation group from $0.85(0.34) \mathrm{nmol}$ to $0.96(0.19) \mathrm{nmol}$. This observed increase attenuated during the three months of low dose supplementation (0.93 (0.22) nmol; table 2).

Table 2 Main outcome variables before and after $\beta$-carotene supplementation

\begin{tabular}{|c|c|c|c|c|c|c|c|c|c|}
\hline & \multicolumn{2}{|l|}{ Baseline } & \multicolumn{3}{|c|}{12 weeks supplementation } & \multicolumn{3}{|c|}{24 weeks supplementation } & \multirow[b]{2}{*}{$\begin{array}{l}p \text { value of } \\
\text { the group } \\
\text { factor }\end{array}$} \\
\hline & $\begin{array}{l}\text { Supplementation } \\
\text { group }\end{array}$ & $\begin{array}{l}\text { Placebo } \\
\text { group }\end{array}$ & $\begin{array}{l}\text { Supplementation } \\
\text { group }\end{array}$ & $\begin{array}{l}\text { Placebo } \\
\text { group }\end{array}$ & $\begin{array}{l}\text { CI of group } \\
\text { difference }\end{array}$ & $\begin{array}{l}\text { Supplementation } \\
\text { group }\end{array}$ & $\begin{array}{l}\text { Placebo } \\
\text { group }\end{array}$ & $\begin{array}{l}\text { CI of group } \\
\text { difference }\end{array}$ & \\
\hline $\begin{array}{l}\mathrm{FEV}_{1}(\% \text { pred }) \\
\text { Antibiotic }\end{array}$ & $72.2(32.2)$ & $\begin{array}{l}83.7 \\
(21.1)\end{array}$ & $71.6(34.0)$ & $82.2(15.1)$ & -10.17 to 5.66 & $70.0(33.3)$ & $80.3(19.1)$ & -9.40 to 7.650 & 0.696 \\
\hline days/patient & $14.5(14.9)$ & $10.5(11.2)$ & $9.8(10.3)$ & $24.8(19.1)$ & -35.5 to -2.23 & $10.5(9.9)$ & $18.5(15.8)$ & -26.73 to 3.07 & 0.050 \\
\hline $\begin{array}{l}\text { Total antioxidative } \\
\text { capacity (nmol) }\end{array}$ & $0.85(0.34)$ & $0.86(0.26)$ & $0.96(0.19)$ & $0.87(0.21)$ & -0.003 to 0.607 & $0.93(0.22)$ & $0.90(0.19)$ & -0.204 to 0.346 & 0.196 \\
\hline
\end{tabular}

$\star_{9} \%$ confidence interval for the group difference of the post/pre differences.

$\star \star \mathrm{p}$ value of the group factor from the repeated ANOVA model. 


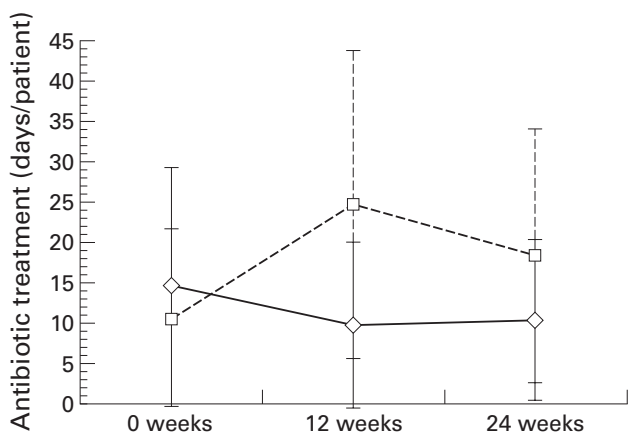

Figure 2 Antibiotic treatment days in the $C F$ supplementation group $(\diamond)$ and placebo group ( $\square$ ) during 12 weeks of high dose treatment and 12 weeks of low dose treatment. Results are mean (SD).

At the beginning of the study MDA concentrations were significantly higher in the patients than in the control subjects $(1.6(0.6)$ versus $1.1(0.4) \mu \mathrm{mol} / 1, \mathrm{p}<0.05) .{ }^{29}$ After three months of high dose supplementation the MDA values of the supplementation group decreased to normal concentrations of $1.1 \quad(0.4) \mu \mathrm{mol} / 1$. However, this positive effect was not sustained during low dose supplementation and MDA concentrations increased to $1.3(0.6) \mu \mathrm{mol} / 1$. No comparison between the groups was done because of missing values.

A significant increase in height was observed in both groups over the six month period (time trend of the height $\mathrm{z}$ score: $\mathrm{p}=0.045$ ). The height $\mathrm{z}$ score in the supplementation group increased from a baseline value of -1.13 (1.08) to $-1.04(1.00)$ and in the placebo group from a baseline value of $-1.12(0.75)$ to $-0.81(0.63)$ after 24 weeks.

$\mathrm{FEV}_{1}$ did not change significantly in either group during the 24 weeks (table 2), nor did the other secondary variables (BMI and Shwachmann-Kulczycki score) show any significant group difference or time trend.

Beta-carotene supplementation was well tolerated in all patients. None developed signs of carotenodermia, although some patients reported a better tanning after exposure to sunlight. The plasma retinol concentration of the CF patients was in the lower normal range $(0.8(0.3) \mu \mathrm{mol} / \mathrm{l})$ at the beginning of the study and did not rise during supplementation (0.9 (0.2) $\mu \mathrm{mol} / \mathrm{l})$. Thus, no risk of retinol toxicity even during high dose supplementation could be detected.

\section{Discussion}

There are two major findings in this study. Firstly, $\beta$-carotene supplementation appears to be associated with a clinical benefit for patients with $\mathrm{CF}$ and, secondly, normalisation of the plasma concentration of $\beta$-carotene can only be achieved and maintained with a high dose of $1 \mathrm{mg} / \mathrm{kg} /$ day. To our knowledge this is the first double blind, placebo controlled study to demonstrate a beneficial clinical effect of $\beta$-carotene supplementation in patients with CF.

In $\mathrm{CF}$ progressive lung disease is characterised by chronic endobronchial infection and a chronic, predominantly neutrophilic inflammatory response. Neutrophils-which are maximally stimulated as a result of ineffective phago- cytosis with persistence of endobronchial bacteria, mostly Pseudomonas aeruginosa or Staphylococcus aureus ${ }^{30}$-release large amounts of both reactive oxygen species and proteolytic enzymes, overwhelming the existing protective systems of both antioxidants and antiproteases. ${ }^{31}$ However, neutrophil inflammation was also seen in patients with $\mathrm{CF}$ even in the absence of any endobronchial infection. ${ }^{32}$ Patients with $\mathrm{CF}$ therefore usually receive additional supplementation with the nutrient antioxidants $\alpha$-tocopherol and ascorbate. However, compared with the levels of a healthy population, they also frequently have a decreased plasma concentration of $\beta$-carotene, another nutrient antioxidant. ${ }^{9-11} 2933$ The possible factors which may explain this finding are malabsorption and thus decreased fat soluble vitamin and provitamin intake on the one hand, ${ }^{7119}$ and chronic pulmonary inflammation causing severe oxidative stress which may increase the turnover of nutrient antioxidants, possibly due to their reaction with reactive oxygen derived species, on the other, ${ }^{5}$ resulting in an oxidant-antioxidant imbalance in favour of the former. ${ }^{1-381034}$ It is assumed that this imbalance leads to oxygen free radical induced tissue injury mediated by an attack on unsaturated fatty acids of lipid structures as well as proteins, especially enzymes and DNA. ${ }^{35}$ Evidence of increased lipid peroxidation, the most frequently assessed aspect of such an attack, was detectable in our study population and has been published previously. ${ }^{29}$ It is speculated that, in patients with CF, lipid peroxidation products, in addition to the large amount of neutrophil elastase in the airways, may overwhelm the neutralising capacity of the proteinase inhibitor $\alpha_{1}$-PI due to oxidative inactivation, as has been shown in an in vitro study. This harmful effect was prevented by addition of various antioxidants including vitamins $C$ and $\mathrm{E}^{36}$ The usual supplementation with retinol, $\alpha$-tocopherol and ascorbate, however, does not appear to reduce the markedly increased parameters of lipid peroxidation sufficiently. ${ }^{7-9} 111431$ Recent clinical data show that patients with CF who are sufficiently supplemented with vitamin $\mathrm{E}$ but with an uncorrected $\beta$-carotene deficiency still exhibit increased lipid peroxidation. ${ }^{7816}$

Our data show that only during the three months of supplementation with $1 \mathrm{mg} / \mathrm{kg} /$ day $\beta$-carotene could plasma concentrations be maintained in a range that was associated with a decrease in the initially raised levels of MDA - a marker of lipid peroxidation-to values equal to those of healthy individuals. This positive influence of $\beta$-carotene supplementation on parameters of lipid peroxidation has already been reported in earlier studies. $^{7810131619}$ The main purpose of the present study, however, was to asses whether normalisation of the plasma concentration of $\beta$-carotene might also be associated with a clinical benefit. We therefore evaluated the number of antibiotic treatment days necessitated by an acute pulmonary exacerbation.

The need for systemic antibiotics for treatment of an acute exacerbation in the $\beta$-carotene group was significantly lower than in the placebo group and, indeed, the placebo group showed an 
increase in the number of antibiotic treatment days. This increase was not entirely unexpected since the study period coincided with the cold season and most of the patients were included during autumn and winter months. We hypothesise that, by normalising plasma concentrations of $\beta$-carotene, together with improved lipid peroxidation, the antioxidative-oxidative imbalance might be corrected, providing better protection and thus reducing the susceptibility to pulmonary exacerbations.

There were no changes in $\mathrm{FEV}_{1}$ during the study period in either group and no changes in the Shwachmann-Kulczycki score, with no significant differences between the supplementation and placebo groups. These findings must be interpreted with caution because of the small number of patients. The frequent follow up visits on a monthly basis and our strict regime of treating pulmonary exacerbations immediately with antibiotics according to the results of microbiology tests may be another explanation why no changes in lung function or Shwachmann-Kulczycki score were detected during the six months of the study.

No adverse events were observed during the study and $\beta$-carotene was well tolerated. This is in agreement with Winkelhofer-Roob et al who also found no serious adverse effects in their $\beta$-carotene supplementation study over 16 months. ${ }^{19}$

Because of the small number of patients and the high variability in clinical presentation, a characteristic phenomenon in patients with $\mathrm{CF}$, our data must be treated with caution. Yet, our first data from this pilot study appear to be encouraging enough to justify further studies to assess the clinical effects of $\beta$-carotene supplementation in a larger cohort of patients. However, in the light of previous studies ${ }^{37} 38$ indicating an increased risk of lung cancer in smokers after 5-8 years of dietary $\beta$-carotene supplementation, any long term supplementation with $\beta$-carotene must be followed closely and cautiously.

In conclusion, our data demonstrate that oral $\beta$-carotene supplementation in a dose of $1 \mathrm{mg} /$ $\mathrm{kg} /$ day is effective in normalising $\beta$-carotene plasma concentrations and the parameters of lipid peroxidation. This normalisation is associated with a clinical benefit by significantly decreasing the number of days of antibiotic treatment necessitated by acute pulmonary exacerbations. Our data suggest that patients with CF may benefit from oral $\beta$-carotene supplementation.

1 Berger $M$. Inflammation in the lung in cystic fibrosis. A vicious cycle that does more harm than good? In: Gershwin $\mathrm{E}$, ed. Clinical reviews in allergy, Vol 9: Cystic fibrosis. Humana Press, 1991:119-42.

2 Babior BM. The respiratory burst oxidase. Trends Biomed $S \mathrm{C}$ 1987;12:241-3.

3 Meyer KC, Lewandoski JR, Zimmermann JR, et al. Human neutrophil elastase and elastase/alpha-1-antiprotease complex in cystic fibrosis. Am Rev Respir Dis 1991;144:580-5.

4 Salh B,Webb K, Guyan PM, et al. Aberrant free radical activity in cystic fibrosis. Clin Chim Acta 1989;181:65-74.

5 Van der Vlient A, Eiserich JP, Marelich GP, et al. Oxidative stress in cystic fibrosis: does it occur and does it matter? Advan Pharmacol 1997;38:491-513.

6 Winklhofer-Roob BM, Ellemunter H, Fruewirth M, et al. Plasma vitamin C concentrations in patients with cystic fibrosis: evidence of associations with lung inflammations. Am 7 Clin Nutr 1997;65:1858-66.

7 Winklhofer-Roob BM, Puhl H, Khoschsorur G, et al. Enhanced resistance to oxidation of low density lipopro- teins and decreased lipidperoxid formation during -carotene supplementation in cystic fibrosis. Free Radic 1995;18:849-59.

8 Lepage G, Champangne J, Ronco N, et al. Supplementation with carotinoids corrects increased lipid peroxidation in children with cystic fibrosis. Am F Clin Nutr 1996;64:87-93.

9 Portal BC, Richard MJ, Faure HD, et al. Altered antioxidant cystic fibrosis. Am f Clin Nutr 1995;61:843-7.

10 Winklhofer-Roob BM, Schlegel-Haneter SE, Khoschsorur G, et al. Neutrophil elastase/alpha 1-proteinase inhibitor complex levels decrease in plasma of cystic fibrosis patients during long-term oral beta-carotene supplementation. Pediatr Res 1996;40:130-4

11 Götz M, Bartens C, Elmadfa I. Antioxidant status in cystic fibrosis (CF) patients with chronic pulmonary inflammation. Pediatr Pulmonol 1993;1:281.

12 Homnick DN, Cox JH, DeLoof MJ, et al. Carotenoid levels in normal children and in children with cystic fibrosis. $\mathcal{F}$ Pediatr 1993;122:703-7.

13 Homnick DN, Spillers CR, Cox SR, et al. Single-and multiple-dose-response relationships of beta-carotene in cystic fibrosis. F Pediadr 1995;127:491-4

14 Sokol R. Do CF patients need fat soluble vitamins? Pediatr Pulmonol 1989;4:63-5.

15 Peters SA, Kelly FJ. Vitamin E supplementation in cystic fibrosis. F Pediatr Gastroenterol Nutr 1996;22:341-5.

16 Lepage G, Ronco N, Champagne J, et al. Betacarotene inhibits lipid peroxidation and improves peroxismal function in cystic fibrosis. FASEB f 1993;7: A39.

17 Bendich A. Antioxidant micronutrients and immune responses. Ann NY Acad Sci 1990;387:168-80

18 Anderson R, Theron AJ. Physiological potential of ascorbate, $\beta$-carotene and $\alpha$-tocopherol individually and in combination in the prevention of tissue damage, carcinogenesis and immune dysfunction mediated by phagocyte-derived reactive oxidants. In: Bourne $\mathrm{GH}$, ed. Aspects of some vitamins, minerals and enzymes in health and disease. Basel: Karger, 1990: 27-58.

19 Winklhofer-Roob BM, Van't Hof MA, Shmerling DJ. Response to oral $\beta$-carotene supplementation in patients Response to oral $\beta$-carotene supplementation in patients with cystic fibrosis: a $16-$
Paediatr 1995;84:1132-6.

20 Gibson LE, Cooke RE. A test for concentration of electrolytes in sweat in cystic fibrosis of the pancreas, utilizing pilocarpine by iontophoresis. Pediatrics 1959;23:545-9.

21 Shwachman H, Kulczycki LL. Long term study of one hundred and five patients with cystic fibrosis. Am $\mathcal{F}$ Dis Child 1958;96:6-15.

22 American Thoracic Society. Standardisation of spirometry: 1987 update. Am Rev Respir Dis 1987;136:1285-98.

23 Zapletal A, Samanek M, Paul T. Lung function in children and adolescence: methods, reference values. Prog Respir Res 1987;22:113-218.

24 Prader A, Largo RH, Molinari L, et al. Physical growth of Swiss children from birth to 20 years of age. Helv Paediatr Acta 1989;52:1-125.

25 Jakob E, Elmadfa I. Rapid HPLC assay for assessment of vitamin $\mathrm{K} 1, \mathrm{~A}, \mathrm{E}$ and beta-carotene status in children (7-19 years). Int $\mathcal{F}$ Vit Nutr Res 1995;65:31-5.

26 Rice-Evans K, Miller N. Total antioxidant status of in plasma and body fluids. Methods Enzymol 1994;234:279-93.

27 Halliwell B, Chirico S. Lipid peroxidation: its mechanism, measurement, and significance. Am f Clin Nutr 1993;57: 715-25S.

28 Wong SHY, Knight JA, Hopfer SM, et al. Lipoperoxides in plasma as measured by liquid-chromatographic separation plasma as measured by liquid-chromatographic separation 1987;33:214-20.

29 Rust P, Eichler I, Renner S, et al. Effects of long term oral $\beta$-carotene supplementation on lipid peroxidation in patients with cystic fibrosis. Int $\mathcal{F}$ Vit Nutr Res 1998;68:83-7.

30 Eichler I, Joris L, HsuYP, et al. Nonopsonic antibodies in cystic fibrosis. F Clin Invest 1989;84:1794-804.

31 Winklhofer-Roob BM. Oxygen free radicals and antioxidants in cystic fibrosis, the concept of an oxidantantioxidant imbalance. Acta Pediatr 1994;395:49-57.

32 Khan TZ, Wagener JS, Bost T, et al. Early pulmonary inflammation in infants with cystic fibrosis. Am f Respir Crit Care Med 1995;151:1075-82.

33 Winklhofer-Roob BM, Van't Hof MA, Shmerling DJ. Reference values for plasma concentrations of vitamin $\mathrm{E}$ and $\mathrm{A}$ and carotinoids in a Swiss population from infancy to adulthood, adjusted for seasonal influences. Clin Chem 1997;43:146-53.

34 Brown RK, Kelly FJ. Role of free radicals in the pathogenesis of cystic fibrosis. Thorax 1994;49:738-42.

35 Reilly PM, Schiller HJ, Bulkley GB. Pharmacologic approach to tissue injury mediated by free radicals and other reactive oxygen metabolites. Am f Surg 1991;161: 488-503.

36 Mohsenin V, Gee JBC. Oxidation of $\alpha_{1}$ proteinase inhibitor: role of lipid peroxidation products. $\mathcal{F}$ Appl Physiol 1989;66: 2211-5.

37 Heinonen O, Albanes D on behalf of the Alpha-Tocopherol, Beta Carotene Cancer Prevention Group. The effect of vitamin $\mathrm{E}$ and beta carotene on the incidence of lung cancer and other cancers in male smokers. N Engl f Med 1994; 330:1029-35.

38 Omenn GS, Goodman GE, Thornquist MD, et al. Risk factors for lung cancer and for intervention effects in CARET, the Beta-Carotene and Retinol Efficacy Trial. $\mathcal{F}$ Natl Cancer Inst 1996;88:1550-9. 